\title{
Effects of Covid-19 on Healthcare Industry and Public Health Infrastructure
}

\author{
Nasim Ahmad and Swaroopa Chakole \\ Intern,Dept.of Community Medicine, Jawaharlal Nehru Medical College, Datta Meghe \\ Institute of Medical Sciences (Deemed to be University), Sawangi (Meghe), Wardha-442001. \\ Corresponding author email: drswaroopachakole@gmail.com
}

\section{ABSTRACT}

The year 2020 has witnessed the worst pandemic of the century with millions of deaths throughout the world due to COVID-19 and associated complications and crisis. In addition, mutations in the viral strain aggravated the panic.Testing, tracking and treating protocols were standardized and followed to mitigate the transmission and conceal the spread. The treatment strategy of COVID-19 included containment model with special healthcare facility and isolation of the infected for 2 weeks. The preexisting gaps in available healthcare infrastructure and government funding to tackle such pandemic were uncovered. Many critical decisions and resource mobilization in a timely manner was needed for strengthening the healthcare facilities around the world. A thorough remake of healthcare facilities with anticipated caseload is needed apart from availing trained manpower to handle the situation and benefitting all sections of the society.

KEY WORDS: INDIA, DEVELOPING COUNTRY, COVID-19, HEALTHCARE, INFRASTRUCTURE.

\section{INTRODUCTION}

COVID-19 is emerging as the biggest threat to humanity during past century. It is cause by SARS-COV-2 which is also known as coronavirusdue to its spike shaped proteins and crown shaped structure( Dushyant , 2020) and is the new entrant in the family of the coronavirus. Severe acute respiratory syndrome (SARS)( Ngai, 2020) and Middle Eastern respiratory syndrome (MERS) are the previous outbreaks that had wreaked havoc already but were contain within a certain geographical area( Batawi et al., 2020). Till date by December 27, 2020 coronavirus induced infection has covered 80,431,748 registered cases worldwide in more than 190 countries and registered 1,759,358 deaths due to COVID-19 complications(4).

Biosc Biotech Res Comm P-ISSN: 0974-6455 E-ISSN: 2321-4007

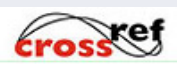

Identifiers and Pagination

Year: 2021 Vol: 14 No (6) Special Issue

Pages: 164-169

This is an open access article under Creative

Commons License Attribn 4.0 Intl (CC-BY).

DOI: $h t t p: / / d x . d o i . o r g / 10.21786 / b b r c / 14.6 .36$
This impact was so huge that World Health Organization (WHO) on March 11, 2020, declared the COVID-19 epidemic as pandemic(5) which was designated as public health emergence of international concern (PHEIC). United States of America, India, Brazil, Russian federation, France and United Kingdom are the worst affected countries having more than half of total number of infection that is registered worldwide(6). Recent reporting of new mutated strain of the coronavirus from United Kingdom and from South Africa has increased the worries of the researchers and mitigating agencies as it is said to be more virulent than the previous strain of the virus( Wise, 2020). The severity was highlighted and many governments started imposing movement restriction and lockdown as the COVID-19 was found out to be extremely contagious and spreading like a wild fire.

The comorbid patients are at high risk in developing the severe symptoms of the COVID-19 in due course of treatment. Various tests are used to diagnose the patients among which RT-PCR test is widely accepted and considered as golden standards. The main aspect of the COVID-19 implications that needs to be mention is

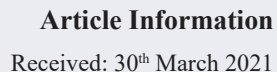
ccepted after revision: $27^{\text {th }}$ May 2021 
crumbling of the health care infrastructure which is the back bone containment formula, trace, test and treat. The hospitals and other COVID-19 care facilities were overwhelmed as the lockdown started to ease up(Schütte, 2020). Movement of people resulted in rapid transmission of the infection and overwhelmed already ailing health care infrastructure.

The fault line was left wide open not only in developing and least developed nations but also in developed countries to where the health care facilities are said to be up to date. Countries like India where health care facilities are not too good are worry due to immense population density and urban slum clusters that may catch infection and become hotspot and it would be impossible to deal with such scenario. The impact of COVID-19 on nonCOVID-19 patients are widely being notice and should be not culminated into epidemic within pandemic. Another part of health care infrastructure are health care workers. They are severely strained, mentally as well as physically and needs to be looked upon properly. Post COVID-19 implications are also gaining grounds as a year is pass since the inception of the virus. A lot resources are repurposed and diverted to the containment of the COVD-19 and this left other critical sectors vulnerable to various problems. In this article we are going to discuss these topics in detail and try to interlink the topic to get a holistic overview.

Health Care System Around he World: Health care infrastructure and system of function is different around the world. There can be seen stark difference among least developed countries, particularly African countries, developing countries particularly Asian countries and developed countries particularly western countries which have advance infrastructure in health service domain. In poorer countries where even basic health services are not present and they have to deal with every other disease outbreak, developed countries have state of the art facilities. Also, social security protection in times of health crisis is absent in poor countries where as rich countries ensures their citizen in form of any health protection scheme and if they get sick, theirmedical expense can be taken care of through insurance up to certain extent.

This provides a sense of relief and people in such countries can work for their overall development. Whereas only small and petty disease can bring the poorer country's citizen below poverty line again if they are marginally above it (Konwar et al., 2020). Maternal mortality rate (MMR) and Infant Mortality Rate (IFR) are high in underdeveloped countries due to non-institutional deliveries of the baby and following of unsafe practices. Easily preventable disease like diarrhea, measles etc. can wreak havoc in low-income countries as their citizens are not financially stable and health infrastructure is not able to cope up even with small pressure. For example, even the Ebola outbreak saw huge case fatalities before it got controlled due to international help that was poured in after the sad pictures emerging out of the African countries.
Concept of health is very much linked to the educationas education index goes up, health bettermentalso goes up. Manytopics of personal and surrounding hygiene are picked up by the people from educational textbooks and are with them lifelong helping them to remain disease free. Health expenditure are by governments and public authorities are decreasing day by day and private players are taking over bringing in more advanced methods of treatment and treatment on very complex disease which can increase the longevity of the person. But the affordable primary health care service is receding and also a cause of concern. The COVID-19 pandemic has shown as how accessible health care can prove boon in containing the viral spread. The decentralized approach is the key and therefore the ground level health care facilities must strengthen in order to efficiently deal with future such scenarios( Konwar, 2020).

Health Care System in India and Universal Health Coverage: The health care system in India is three tiered. Primary level health care system, secondary level health system and tertiary level health care system. Both public and private entity are in all three sectors with varying degrees. Primary health centers (PHC'S) are mostly handled and run by the public entities for example governments and secondary has more public private partnerships whereas tertiary sector is dominated by private sector at urban locations although some public sector involvements are also seen. The universal health care model is adopted by India and mostly administered by states than union or central authorities as according to the division of power between center and states, health care is state subject. In 2019 the total health care spending by government from the budget was 1.36 percent of the GDP which accounts for around USD 36 billion.

Although the public health care system is free for all but access to it a challenge. In addition, the quality of health service provided by the public health service provider is not matching with threshold standard and only poorer and marginalized sections of the society avail some benefits from it. Lower and upper middle class tend to go to private clinic as the assurance of quality service is there plus, they can afford it as private health care service is costly. Inaccessibility is one of the reasons along with inadvertent hours of operations, unavailability of manpower and inadequate equipment's which results into long waiting hours. The private sector dominates in urban localities and accounts for more than 70 percent treatment of overall populations that seek one. The gradual increase in income level is linked with more use of private health care units and improved lifestyles and quality of life. But as the COVID-19 pandemic hits these increase in overall income level gains may vanish soon as many livelihoods are lost and any private health expenditure will render these slightly above poverty line families again below poverty line.

Therefore, it is important to strengthen the public health care system particularly rural area health infrastructure so that they can access a quality healthcare 
with affordable prices. Quackery, blind faith, tantric activities may hamper the efforts of providing good quality healthcare to all people especially rural areas (Chetterje, 2020). COVID-19 has crumbled the health sector not just in developing countries like India but also in developed countries as well such as Italy and United States of America. The coronavirus has cut across the spectrum and even sophisticated health care system were not able to prevent the menace of the COVID-19. The case fatalities are the witness of that.

The concept is universal health coverage is often talked about but less implemented. As the opening up of the health sector to private firms brings new technologies and innovation particularly in research and development. But it has also its limitations too. As the entry of private entities is only depends upon profits and virtually there is no chance for any leeway for poorer and marginalized sections. In the COVID-19 the exact same thing was highlighted and now the time has come to address this anomaly. The poorer section was more affected by the pandemic as they have lesser means to tackle the problem, they did not even start at first place. Private firms and hospitals do not allow the poorer section to be treated and this creates a confrontation. Public health service remains the only option that is availing to the poorer section of the society and which is quite underfunded.

Low penetration of insurance among lower starts make sis more difficult to cover their medical expense and leading to fatal condition. Ramping up the government expenditure up to certain level to which below poverty line persons may be ensured that someone is there to take care of his or her medical conditions and also is his or her right to get affordable medical treatment. Also insuring the people can also get them treated in private hospitals as their medical expense is all covered under the insurance scheme. Universal health coverage is the need of the hour and no one should be denied basic treatment which is their right and they deserve to get it.

Impact of Covid-19 On Non-Covid-19 Patients: The only thing which was focused upon was how to contain the viral spread of COVID-19. The extremely virulent virus has already caused many casualties and more devastating and hidden impacts are uncovering day by day. It also includes the impact of COVID-19 on non-COVID-19 patients. Almost all critical to primary health services are repurposed for mitigating the COVID-19. In addition, the lockdown induced movement restrictions also made the health services to non-COVID-19 patients inaccessible. The number of hysterectomies was drastically reduced among women, cesarean section in maternity conditions also reduced hinting towards non-institutionaldeliveries of babies which is quitea cause of concern, non-urgent surgeries such as inserting coronary stents, angiography, knee replacements, cosmetic surgeries saw almost complete reduction as all the available facilities were diverted to treat the COVID-19 patients.

Also, people were scared of getting contracted with the infection as the virus is extremely contagious. Regular health check-ups were almost zero. Casualties also saw reduction such as road accidents and injuries as vehicle were barred during lockdown and prohibitory orders were imposed. The pandemic has forced people to change the habits and lifestyle of theirs for good or perish. Many started to exercise and yoga, eat healthy, cut down on high sugar and fat foods and quitting bad habits such as smoking and drinking liquor. This may induce positive impact and in continues we will be ready for future such pandemic (Rosenbaum, et al., 2020).

Impact on Health Care Professionals: The health care workers and professionals are the key point in mitigating the COVID-19 menace. They are the front-line workers and actually deals with the infected patients, exposing them to the chance of getting infected on duty. Lots of casualties have been repotted among doctors(13) and nurses. According to International Nurses Council, more nurses has died during COVID-19 mitigation duty than during First World War(14). Thishighlights the plight of the health care professionals(15). Also, a less talked about factor of mental pressure and psychological stress were also prevalent among doctors and nurses as they are under constant fear of transmitting the virus to their family members and their loved ones. They are also the part of the health infrastructure and needs to be protected at any cost.

Long duty hours wearing the personal protective equipment's (PPE) kits which are certainly not comfortable increases the anxiety levels in any professionals. In some cases, it was found that the proper PPE kits were not provided and health care professionals were left exposed to the infection of the virus. Extremely negative impact was observed as some of their colleagues died due to COVID-19 complications. Already the required manpower is way lower than the expected and desired ones and losing even one health care professional may prove devastating. During initial days, doctors and other health care professionals were subjected to extreme treatment such as home evictions, abuses, and boycott only due to misinformation's that caused by the extra time spent on the social media. This situation later turned in favor of doctors but the act was inhumane and condemnable howsoever it may unintentional (Baggish, et al., 2020).

Divergence of the Resources and Non-Covid-19 Patients: The pandemic has severely broken the backbone of the health care infrastructure all across the globe. Even developed countries are reeling under the pressure of lack of facilities to provide. The mass and scale of the pandemic is huge and unprecedented and we as a humanity were not prepared for such scenarios. Whether a country doing good on social indicators or not, whether the social security net of that country covers maximum people or not, the pandemic of the COVID-19 has affected severely in all cases the same. Be it Italy, Spain or brazil and India, no one thought that so much strain will accumulate on the current capacity of the health care facilities and were soon crumbled in front of virus's fury. The virulence was huge and lethal nature of 
the COVID-19 made governments to divert all the funds from other medical care system to the containment of the COVID-19.

Almost all health care facilities were only treating the COVID-19 patients or they were closed down as opening up other facility would invite another super spreading events. All non-COVID-19 patients' surgery were either postpones or cancelled due to unavailability of the health professionals that were currently mitigating the viral spread. In fact, comorbid patients were not allowed to go out in initial days of the pandemic as they fell in the vulnerable section people who can catch the infection and develop severe symptoms that can prove fatal.

Post Covid-19 Health Care: The COVID-19 treatment merely not gives the infected person certificate of illness free instead there are grave post illness complications arising out of COVID-19. As the coronavirus belongs to the SARS-COV family of the virus, therefore post illness complications are bound to arise as was arisen in case of severe acute respiratory syndrome (SARS) and Middle Eastern respiratory syndrome (MERS). Both were showing long term disorders like fatigue, weakening of the cardiovascularmuscle, lowered physical ability post discharge from the care facility(17). Therefore,itis important to be ready to deal with the post COVID19 phenomena that may linger even after complete defenestration of the disease from the society.

Elderly, persons with comorbidities and persons with temporary immunosuppressive state like new born babies and their mothers, pregnant women are all unsafe and needs to be taken care of. The post illness complications can seriously affect the persons over all wellbeing also inducing psychological distress because of long treatment and due to not coping up with the current lifestyle. COVID-19 seriously hampers physical capacity of the person affected. Athletes may be most affected as their work related to more physical activity (Rastogi et al., 2020). Post COIVID-19 rehabilitative care needs to be established so that it can be accessed by anyone who are in need. Dedicated and not shared facilities can erected or be converted and proper dissemination of information about the said facility needs to be done in order tackle the problem of post COVID-19 illness.

Often underwritten impact that psychological impact can be tackle by employing counsellors and coupling them to certain number of patients who can then dedicatedly monitor the patient's mental wellbeing and be acquaint of the overall nature of the patient. Same psychologists or competent professionals treating the patient may be benefitting the patient more as compared to changing one(19).Manny studies were reported from this region on different aspects of Covid-19 .(Wanjari et. al., 2020) reported a case of COVID 19 presenting as fatal subarachnoid hemorrhage. (Spoorthy et. al., 2020) reflected on mental health problems faced by healthcare workers due to the COVID-19 Pandemic. (Singh et.al., 2020) addressed the issues of Covid-19 associated coagulopathies and the significance of thrombotic prophylaxis in critically ill patients(32). Some interesting studies by (Singh et.al. 2020; Sharma et. al. 2020; Sawarkar et.al. 2020)were reviewed.

\section{CONCLUSION}

The coronavirus gave us bruises physically as well as mentally that will take time to heal. But the health care infrastructure needs to be strengthened to ensure that future pandemic, if arrives, can be dealt with efficacy as according to WHO, COVID-19 pandemic is not the last pandemic that humanity as faced. Health care professionals should be given adequate resting time and proper PPE kits in order to safeguard them from any exhaustion. Counsellors can be appointed so that emotional wellbeing can be maintained. Post COVID-19 implications are frightening and needs urgent measures from ow onwards. As various post illness disorders are being reported it is necessary to take into account those grievances and starts to invest in post COVID-19 rehabilitative infrastructure. Divergence of funds and resources is temporarily justifiable but not sustainable in the long term.

We cannot afford to invite another epidemic in pandemic as the non-COVID-19 patients are neglected and sidelined. Proper inclusion of them into the plan should be necessary and special efforts are needed in order to include them in medical interventions which they are in dire need. Lastly this infection can be controlled by various preventive measures which needs to adopted and promoted so that the disease is prevented from happening from first place. Although there is some news about various vaccine candidates are in final stage and ready to be distributed but it will take considerable amount of time to distribute to approximately 7 billion inhabitants of the earth. Till then we have to take care of ourselves and better be adopting good and hygienic habits in order to successfully ward off the infection.

\section{REFERENCES}

A S, A S. Is India's Health Care Infrastructure Sufficient for Handling COVID 19 Pandemic? https://www. clinmedjournals.org/articles/iaphcm/internationalarchives-of-public-health-and-community-medicineiaphcm-4-041.php?jid=iaphcm

Attacks on health care in the context of COVID-19 https://www.who.int/news-room/feature-stories/detail/ attacks-on-health-care-in-the-context-of-covid-19

Baggish A, Drezner JA, Kim J, Martinez M, Prutkin JM. 2020 Resurgence of sport in the wake of COVID19: cardiac considerations in competitive athletes. Br J Sports Med [Internet]. https://www.ncbi.nlm.nih.gov/ pmc/articles/PMC7513253/

Batawi S, Tarazan N, Al-Raddadi R, Al Qasim E, Sindi A, AL Johni S, et al. 2020 Quality of life reported by survivors after hospitalization for Middle East respiratory syndrome (MERS). Health Qual Life Outcomes https:// doi.org/10.1186/s12955-019-1165-2 
Chetterje P. Gaps in India's preparedness for COVID-19 control. Lancet Infect Dis [Internet]. https://linkinghub. elsevier.com/retrieve/pii/S1473309920303005 COVID-19 Map [Internet]. Johns Hopkins Coronavirus Resource Center. [cited 2020 Dec 27]. Available from: https://coronavirus.jhu.edu/map.html

Dushyant Bawiskar, Pratik Phansopkar, Ayurva Vilas Gotmare. 2020 COVID-19 Facets: Pandemics, Curse and Humanity. Int J Res Pharm Sci. 6;11(SPL1):385-90. Ensuring health equity during the COVID-19 pandemic: the role of public health infrastructure [Internet]. Pan American Journal of Public Health; [cited 2020 Dec 26]. Available from: https://www.paho.org/journal/ en/articles/ensuring-health-equity-during-covid-19pandemic-role-public-health-infrastructure Gaidhane S, Khatib N, Zahiruddin QS, Gaidhane A, Telrandhe S, Godhiwal P. 'Depression, anxiety and stress among the general population in the time of COVID-19 lockdown: A cross-sectional study protocol.' International Journal of Research in Pharmaceutical Sciences, 11(1), 2020, pp. 360-364.

Green A. A tribute to some of the doctors who died from COVID-19. https://www.thelancet.com/journals/lancet/ article/PIIS0140-6736(20)32478-8/abstract

ICN confirms 1,500 nurses have died from COVID19 in 44 countries and estimates that healthcare worker COVID-19 fatalities worldwide could be more than 0,00https://www.icn.ch/news/icn-confirms1500-nurses-have-died-covid-19-44-countries-andestimates-healthcare-worker-covid

Jachak, S., P. Phansopkar, and M. Waqar Naqvi. "Impact of Covid-19 in India, a Disastrous Pandemic Outbreak.” International Journal of Research in Pharmaceutical Sciences 11, no. Special Issue 1 (2020): 399-402. https:// doi.org/10.26452/ijrps.v11iSPL1.2735.

Joseph, M.B., S. Pohekar, A. Raut, and M. Patil. 2020 "The Palliative Care and Covid-19 Pandemic." International Journal of Research in Pharmaceutical Sciences 11: 618-22. https://doi.org/10.26452/ijrps. v11iSPL1.2861.

Joshi, K., N. Acharya, S. Acharya, and S. Joshi. "A Grave Situation with COVID in the Gravid: A Narrative Review." International Journal of Research in Pharmaceutical Sciences 11, no. Special Issue 1 (2020): 496-99. https://doi.org/10.26452/ijrps.v11iSPL1.2837. Khatib, M.N., S. Gaidhane, M. Khatib, M. Ahmed, A. Gaidhane, and Z.Q. Syed. 2020 "SARS-CoV and SARSCoV-2: Similar Viruses with Different Trajectories.” Wutan Huatan Jisuan Jishu 16: 544-48.

Kim G, Wang M, Pan H, H Davidson G, Roxby AC, Neukirch J, et al. 2020 A Health System Response to COVID-19 in Long-Term Care and Post-Acute Care: A Three-Phase Approach. J Am Geriatr Soc. 2020
Jun;68(6):1155-61.

Konwar AN, Borse V. Current status of point-of-care diagnostic devices in the Indian healthcare system with an update on COVID-19 pandemic. Sens Int http://www.sciencedirect.com/science/article/pii/ S2666351120300152

Lakhkar, B.B., B. Guru, S. Damke, and S. Damke. 2020 "Most Susceptible Duo in COVID-19 Crisis: A Literature Review." Perinatology 21: 112-23.

Latchoumi, T.P., Ezhilarasi, T.P. and Balamurugan, K., 2019. Bio-inspired weighed quantum particle swarm optimization and smooth support vector machine ensembles for identification of abnormalities in medical data. SN Applied Sciences, 1(10), pp.1-10.

Nanotkar, L., S. Dhanvij, and A. Joshi. "COVID-19 and Importance of Social Distancing." Journal of Critical Reviews 7, no. 8 (2020): 1103-4. https://doi. org/10.31838/jcr.07.08.232.

Ngai J C, Ko FW, Ng SS, To K-W, Tong M, Hui DS. 2020 The long-term impact of severe acute respiratory syndrome on pulmonary function, exercise capacity and health status. Respirol Carlton Vic. 15(3):543-50. Nisargandha, M.A., and S. Dadaraoparwe. "Spread of Coronavirus Disease 2019 (COVID-19) during the Lockdown in the Indian Population and Preventive Measures." International Journal of Research in Pharmaceutical Sciences 11, no. Special Issue 1 (2020): 328-32. https://doi.org/10.26452/ijrps.v11iSPL1.2721. Rastogi A, Tewari P. 2020 Covid 19 and its cardiovascular effects. Ann Card Anaesth [Internet]. 2020 0ct 1 https:// www.annals.in/article.asp?issn=0971-9784; year=2020; volume $=23 ;$ issue $=4 ;$ spage $=401 ;$ epage $=408 ;$ aulast $=$ Rast ogi; type $=0$

Rosenbaum L. The Untold Toll - The Pandemic's Effects on Patients without Covid-19. Malina D, editor. N Engl J Med [Internet]. 2: http://www.nejm.org/doi/10.1056/ NEJMms2009984

Sahu, A., and W.M. Naqvi. "Floating Countries and Corona Pandemic: Impact of Covid-19 on Stranded Cruise Ships." International Journal of Research in Pharmaceutical Sciences 11, no. Special Issue 1 (2020):

219-23. https://doi.org/10.26452/ijrps.v11iSPL1.2702. Sawarkar, Gaurav, PunamSawarkar, and Vaishali Kuchewar. 2020 “Ayurveda Students' Perception toward Online Learning during the COVID-19 Pandemic." JOURNAL OF EDUCATION AND HEALTH PROMOTION. https://doi.org/10.4103/jehp.jehp_558_20.

Schütte S, Acevedo PNM, Flahault A. Health systems around the world - a comparison of existing health system rankings. J Glob Health https://www.ncbi.nlm. nih.gov/pmc/articles/PMC5857204/

Shah, P., and W. Naqvi. "Fighting and Chasing the Rogue 
Virus-Covid19.” International Journal of Research in Pharmaceutical Sciences 11, no. Special Issue 1 (2020): 77-80. https://doi.org/10.26452/ijrps.v11iSPL1.2219.

Sharma, Ranjana Premnath, Savitha BasiramPohekar, and RuchiraShirkantAnkar. 2020 "Role of a Nurse in COVID-19 Pandemic.” JOURNAL OF EVOLUTION OF MEDICAL AND DENTAL SCIENCES-JEMDS 9: 2550-55. https://doi.org/10.14260/jemds/2020/554.

Singh, Kumar Tathagat, Gaurav Mishra, Alok Kumar Shukla, Subasish Behera, Arun Kumar Tiwari, SubhasishPanigrahi, and Kumar Gaurav Chhabra. 2020 "Preparedness among Dental Professionals towards COVID-19 in India." PAN AFRICAN MEDICAL JOURNAL 36. https://doi.org/10.11604/pamj.2020.36.108.23694. Singh, Nihaal, Ashish Prakash Anjankar, and Shivangi Garima. 2020 "The Urgent Need to Understand Covid19 Associated Coagulopathies and the Significance of Thrombotic Prophylaxis in Critically Ill Patients." JOURNAL OF EVOLUTION OF MEDICAL AND DENTAL
SCIENCES-JEMDS 9: 2381-85. https://doi.org/10.14260/ jemds/2020/516.

Spoorthy, Mamidipalli Sai, Sree Karthik Pratapa, and Supriya Mahant. "Mental Health Problems Faced by Healthcare Workers Due to the COVID-19 Pandemic-A Review.” ASIAN JOURNAL OF PSYCHIATRY 51 (June 2020). https://doi.org/10.1016/j.ajp.2020.102119.

Wanjari, A. K., Ayush Dubey, Sourav Chaturvedi, and Sunil Kumar. 2020 "Young COVID 19 Presenting as Fatal Subarachnoid Hemorrhage: Association or Chance?" MEDICAL SCIENCE 24: 2712-15.

WHO Coronavirus Disease (COVID-19) Dashboard [Internet]. [cited 2020 Dec 27]. Available from: https:// covid19.who.int WHO Director-General's opening remarks at the media briefing on COVID-19 - 11 March 2020.pdf.

Wise J. Covid-19: New coronavirus variant is identified in UK. BMJ https://www.bmj.com/content/371/bmj. m4857 